\title{
Characteristics of Immigrant Abused Women Who Apply for Legal Status
}

Angeles Nava $^{1 *}$, Judith McFarlane ${ }^{1}$, John Maddoux ${ }^{2}$, Nora Montalvo-Liendo ${ }^{3}$, Heidi Gilroy ${ }^{1}$ and Sandra Cesario ${ }^{1}$

${ }^{1}$ Nelda C Stark College of Nursing, Texas Woman's University, Denton, Texas

${ }^{2}$ Office of Research and Sponsored Programs, Texas Woman's University, Denton, Texas

${ }^{3}$ Friendship of Women, Inc. Brownsville, Texas

"Corresponding author: Angeles Nava, Nelda C Stark College of Nursing, Texas Woman's University, 6700 Fannin Street, Houston, TX 77030, USA, Tel: 713-794-2762; Fax: 713-794-2102, E-mail: u_4Nava@mail.twu.edu

Received date: February 4, 2014, Accepted date: March 28, 2014, Published date: April 4, 2014

Copyright: (c) 2014 Nava A, et al. This is an open-access article distributed under the terms of the Creative Commons Attribution License, which permits unrestricted use, distribution, and reproduction in any medium, provided the original author and source are credited.

\begin{abstract}
Background

Intimate partner violence and undocumented migration are social and health global issues affecting the wellbeing of women.

\section{Purpose}

To document the characteristics of undocumented abused women associated with application for legal status and provide evidence for programs to enable abused, immigrant women to obtain legal status.

\section{Methods}

This study is part of a 7 year prospective study investigating outcomes of 300 abused women who seek help for the first time from safe shelters or the justice system. After informed consent was obtained, women who were English or Spanish speaking, at least 18 year of age, had at least one child between 18 months and 15 years, and who were seeking help for abuse for the first time were entered in the study. For this paper, entry and 16 month follow up data of a subsample of 107 women who reported to be undocumented immigrants and experiencing intimate partner abuse is presented. In addition to demographic information, the interview included the Severity of Violence Against Women Scale, Danger Assessment, Brief Symptom Inventory, Safety Behavior Checklist, Acculturation for Hispanics instrument, Post-Traumatic Stress Disorders, General Self-Efficacy, Koci Marginality Index, and Norbeck Social Support measures.
\end{abstract}

\section{Results}

There was a significant relationship between acculturation and whether or not a woman had applied for legal status, $U=257, Z=-2.61, p=.009$. No significant differences were found in the remaining demographic and outcome measures as a function of having applied for legal status.

\section{Conclusion}

It is important to improve paths and eliminate barriers for undocumented women living with violence to facilitate their legal status. In conclusion, understanding the needs of abused immigrant women will help to develop programs and implement policies to ensure the safety and well-being of these women.

Keywords: Intimate partner violence; Abused women; Immigrant women; Legal status; Undocumented; Acculturation

\section{Introduction}

Intimate partner violence (IPV) and undocumented migration are identified as social and global health issues [1-2]. In 2010, female migrants constituted $49 \%$ of the world's migration [3]. In the United States (US) in 2011, undocumented female immigrants accounted for approximately $45 \%$ of all immigrants [4]. Migration itself is a source of stress [5]. In addition, immigrant women are faced with challenges such as language barriers and discrimination as they arrive to a new country [5]. Violence against women is a major concern with the increased numbers of female migration [5]. In the study by Decker, Raj, and Silverman [6] it was reported that immigrant adolescent females were twice as likely to report recurring sexual abuse compared to non-immigrant girls. Both migration and partner violence have adverse effects on women's physical and mental health [5]. Furthermore, lack of language skills, inadequate knowledge about legal rights, and poor paying jobs hinder immigrant women's ability to 
protect themselves from violence [7]. Immigrant abused women's quest for safety is further complicated by the lack of legal immigration status.

Undocumented immigrant women's status not only increases the vulnerability for abuse, but is also often used by their abusive partners to threaten them with deportation. This is an additional barrier for women to seek help [8-9]. Moreover abused immigrant women who lack legal immigration status are less likely to report violence for fear of consequences [10]. Significant advancement within the last two decades has occurred in efforts to protect abused immigrant women. Currently in the US, immigrant women who are victims of abuse and who meet the criteria may self-petition for a special visa under the Violence Woman Act (VAWA).

\section{Violence Against Women Act and Immigrant Women}

In 1994, Congress first enacted the Violence Against Women Act (VAWA) to address violence against undocumented women. Since VAWA was enacted, improvements have been made to the act to decrease the restriction on qualifying criteria. The VAWA allows eligible abused immigrants to apply for legal status in the United States if the abuser is a US citizen or legal resident [11-12]. An additional path for legal status for abused women is the " $U$ " visa. The $U$ visa is offered to victims of crimes including domestic violence. The applicants must prove that they suffered physical or mental abuse and they must be willing to cooperate with law enforcement in the investigation against the perpetrator [13].

While VAWA is a benefit for abused women, the qualifying criteria are strict and the process is lengthy. In spite of additional provision to improve VAWA, undocumented women face difficulties when applying for legal status. Some of the challenges include the stress of providing a personal detailed statement of the abuse, confusion about the process, amount of evidence needed to prove eligibility, and waiting time to receive documentation [14-15].

\section{Purpose of the study}

The purpose of this research is to explore the association of the characteristics of abused immigrant women who report intimate partner violence and application for legal status. The study provides data to close the gap in literature relevant to undocumented abused immigrant women who strive for a safer and healthier life. More importantly, this study offers evidence for the development of programs to enable abused immigrant women toward legal status.

\section{Methods}

Data utilized in this study comes from data collected as a part of a 7 -year prospective study investigating the outcomes of women seeking partner violence support for the first time through either the justice system or the use of safe shelters. Following Internal Review Board (IRB) approval and with the cooperation of five local safe shelters and the district attorney's office, women who were eligible to participate in this study (i.e., English or Spanish speaking women with at least one child between the ages of 18 months and 15 years old, seeking services for partner abuse for the first time) were approached within 24 hours of first entering either the safe shelter or applying for a protective order through justice services. Women who consented to participate in this study were interviewed at baseline and in four month increments. Data utilized for the present report includes baseline and 16 month follow up data. For a full review of scope, aim, and methodology of the seven year prospected study, see [16].

\section{Instruments}

At each interview, women were asked a series of questions aimed at assessing their mental health (i.e., somatization, depression, anxiety) as measured by the Brief Symptoms Inventory-18(BSI) [17], posttraumatic stress disorder (PTSD) [18], severity of abuse (i.e., threats, physical, sexual; [19)], danger for murder[20]), self-efficacy [21], marginalization [22], social support (i.e., emotional support and tangible support); [23-24] and acculturation status [25]. Across all these measures, higher scores are associated with higher levels of the construct of interest. Specific cut offs per measure vary, and as such, interpretation and meaning will be discussed in later sections of this paper for significant findings. In addition to the aforementioned standardized measures, women were asked if they had or had not applied for immigrant legal status. Demographic information and contextual information (i.e., days at shelter, whether or not the protection orders was received) was also obtained. Time to complete the full interview was approximately 1 hour.

\section{Participants}

An equal number of women $(n=150)$ were recruited from either a safe shelter or the justice services for a total of 300 participants. For the purposes of this study, a subsample of 107(35.7\%) women who self-identified as being immigrants to the United States were analyzed to investigate potential differences in both demographics and outcomes of women who applied for legal immigrant status during the first 16 months of the study. Women included in this subsample had ages that ranged from 18 to 51 , and of these 107 women just over one third ( $\mathrm{n}=22,36.7 \%)$ had applied for legal status at some point during the 16 months following initial contact with either the safe shelter or justice services. Demographic characteristics of the 107 women are outlined in Table 1.

\begin{tabular}{|l|l|l|l|l|l|l|}
\hline & $\mathrm{n}$ & $\%$ & $\mathrm{M}$ & SD & Min & Max \\
\hline Age & 107 & - & 29.44 & 7.35 & 18 & 51 \\
\hline Acculturation & 101 & - & 4.23 & .92 & 1.25 & \\
\hline Group & & & & & & \\
\hline Shelter & 57 & 53.3 & & & & \\
\hline Justice Services & 50 & 46.7 & & & & \\
\hline
\end{tabular}


Citation: $\quad$ Nava A, McFarlane J, Maddoux J, Montalvo-Liendo N, Gilroy H, et al. (2014) Characteristics of Immigrant Abused Women Who Apply for Legal Status. Arts Social Sci J S: S1-001. doi:10.4172/2151-6200.S1-001

Page 3 of 6

\begin{tabular}{|l|l|l|l|l|l|l|}
\hline Primary Language & & & & & & \\
\hline English & 29 & 27.1 & & & & \\
\hline Spanish & 78 & 72.9 & & & & \\
\hline Days at Shelter & & & & & & \\
\hline Less than 21 & 24 & 42.1 & & & & \\
\hline 21 or more & 33 & 57.9 & & & & \\
\hline Protection Order Received & & & & & & \\
\hline No & 19 & 38.0 & & & & \\
\hline Yes & 31 & 62.0 & & & & \\
\hline Applied for legal status & & & & & & \\
\hline No & 38 & 63.3 & & & & \\
\hline Yes & 22 & 36.7 & & & & \\
\hline
\end{tabular}

Table 1. Descriptives of 107 Immigrant Women Reporting Partner Abuse

Note- Percentages shown are valid percentages

\section{Results}

In order to test for significant relationships between whether or not a woman had applied for legal status and categorical variables (i.e., group [shelter, justice services]), primary language (English or Spanish), days at shelter (less than or great than the median of 21 days and whether or not a protection order was received), a series of crosstabulations with Pearson's chi square were conducted. There were no significant relationships between having applied for legal status and the categorical variables. All significant levels were less than 0.05 .

Due to limitations of sample size and violations of the assumption of normality, parametric analyses could not be conducted on the present data. As such, in order to test for differences in continuous demographics and outcome measures, Mann-Whitney $U$ nonparametric analyses were conducted. Please see Table 2 for an overview of outcome variables at 16 month, follow up by legal status application status. As shown, there was a significant relationship between acculturation and whether or not a woman had applied for legal status, $U=257, z=-2.61, p=.009$. Women who had applied for legal status had higher levels of acculturation, $(M=1.77, S D=.82)$ compared to those who did not apply for legal status $(M=1.46, S D=$. 91). Higher levels of acculturation indicate greater use of the English language (i.e., read and write, think, speak); therefore, women who applied for legal status tended to use English more frequently across settings. See Figure 1 for an overview of the differences in these scores. Further Mann-Whitney $U$ tests were conducted across the remaining outcome measures at both intake and 16 month follow up yielding no significant differences as a function of having applied for legal status.

\begin{tabular}{|l|l|l|l|l|l|l|l|l|l|l|}
\hline \multicolumn{9}{|l}{} \\
\hline
\end{tabular}




\begin{tabular}{|l|l|l|l|l|l|l|l|l|l|l|}
\hline Physical Abuse Score & 38 & 21.11 & .65 & 21 & 25 & 22 & 22.41 & 6.61 & 21 & 52 \\
\hline Sexual Abuse Score & 38 & 6.16 & .97 & 6 & 12 & 22 & 6.14 & .64 & 6 & 9 \\
\hline Danger Assessment & 38 & 3.37 & 3.84 & 0 & 18 & 22 & 3.27 & 4.94 & 0 & 22 \\
\hline Marginalization & 38 & 13.47 & 5.30 & 5 & 23 & 22 & 12.73 & 5.47 & 5 & 25 \\
\hline Safety Behaviors & 38 & 4.17 & 1.85 & 0 & 7 & 22 & 4.68 & 1.34 & 2 & 7 \\
\hline Emotional Support & 35 & 3.46 & .78 & 2 & 4 & 20 & 3.24 & .83 & 1 & 4 \\
\hline Tangible Support & 35 & 3.70 & .49 & 2 & 4 & 20 & 3.55 & .76 & 1 & 4 \\
\hline Support Regarding Abuse & 35 & 3.59 & 1.01 & 0 & 4 & 20 & 3.35 & .86 & 1 & 4 \\
\hline Total Functional Support & 35 & 3.58 & .59 & 2 & 4 & 20 & 3.38 & .68 & 1 & 4 \\
\hline
\end{tabular}

Table 2: Means and Standard Deviations of Maternal Outcomes at 16 Months by Application for Legal Status

Note- Means in boldface type indicate significant differences as a function of citizen application, $p<.05$

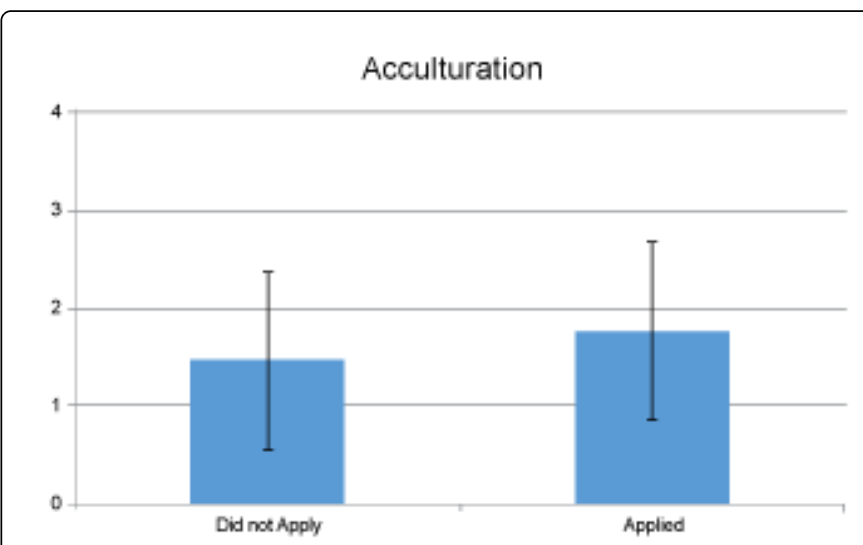

Figure 1: Overview of the differences in scores

\section{Discussion}

Intimate partner violence, migration, and lack of legal immigrant status, have detrimental effects on women's overall well-being. What happens when all these factors are present in a woman's life? What happens when one of these elements is removed, such as legal immigrant status? A significant finding in the study was that women who had applied for legal immigrant status had higher levels of acculturation compared to those who did not apply for legal status. No other research describing the characteristics of immigrant women who apply for legal status was found in the literature. However, previous research indicates that abused immigrant women who are more acculturated are more likely to use safety behaviors but also more likely to experience depression and anxiety [26]. Acculturation is a complex process. The scale used in this study focused only on English language as a proxy to measure level of acculturation. Perhaps being able to communicate in the language of the host country, in this case English, overrides the impact of poor mental health, facilitating a woman to access resources and apply for legal immigrant status. According to Capps, Bachmeier, Fix, and Van Hook [4] 70\% of undocumented adults immigrants have limited or no English language skills. These findings indicate that undocumented abused women may need assistance in English language proficiency to access appropriate resources in moving through the immigration process.

According to the International Organization for Migration, it is critical to create programs and provide assistance for language training and bi-lingual service providers to enable immigrant women [5]. Currently, most of the immigration application forms are in English. A collaborative approach is needed to develop and implement the above mentioned programs to meet the needs of abused immigrant women. Schools and Parent Teachers Organizations (PTO) members can serve as collaborators to develop and implement educational programs [27]. At the same time programs are urgently needed to continue to improve paths and eliminate barriers for undocumented women to obtain employment authorization and to adjust their status [5]. One of the most challenging aspects of applying to a visa for immigrant women is to meet eligibility criteria [14]. More emphasis is needed on increasing knowledge of available legal rights and services specific for abused undocumented women such as VAWA, U-visa, free legal aid, protective orders, and safe shelters. In order to increase reports of violence to authorities and decrease fear of deportation, it is important to identify and use appropriate sources of information about available services. Such sources need to be trusted by undocumented women.

No significant relationships were found between applying for legal status and all outcome and demographic characteristics with the exception of acculturation. Contrary to the results, an expected finding was that abused women who had increased levels of social support, self-efficacy and decreased levels of psychological distress, PTSD, and marginalization, would be more likely to apply for legal immigrant status but no difference was measured in this sample. Ryan and colleagues [28] used BSI to examine levels of distress among a group of people who applied for asylum in Ireland. Unlike the findings in our study, the researchers found that people seeking asylum experienced high levels of distress at entry and follow-up; however, distress decreased in persons who obtain a legal immigrant status. The lack of significant findings in this study may indicate that no significant barriers impede immigrant women from applying for legal status if they decide to do so as long as they are proficient in English.

\section{Limitations}

As with all research limitations to this study exist. This study used language preference as a proxy for acculturation. Other 
multidimensional scales are available to measure acculturation. The potential exists that other measures could reveal different findings with this population. Another limitation is that the sample of immigrant women were primarily from Spanish speaking countries. This sample reflects the immigrant population in the area where the study was conducted. In addition, women were recruited from shelters only for abused women and from the local district attorney's office where they applied for a protection order. Thus, abused immigrant women who accessed help at homeless shelters or who used private legal firms to apply for a PO were not included in this sample. In spite of the limitations, this study contributes to the literature with significant findings about immigrant women who report abuse and documents the need for future research as well as services.

\section{Implications for Future Research}

Research is needed that uses a multidirectional scale to measure acculturation that includes other aspects of acculturation in addition to language. Also studies that include a heterogeneous sample to include abused immigrant women from different parts of the world and who seek help at other types of services, such as counseling.

\section{Conclusion}

Around the world, women are affected by immigration, laws conferring or denying legal immigrant status, and abuse. The findings in this research document women who are more acculturated, meaning have higher English speaking proficiency, are more likely to apply for legal status. And while no other demographic characteristics or outcome measures were significant, the positive acculturation findings indicate that when immigrant abused women possess more English speaking skills, they are much more likely to apply for legal status.

\section{Acknowledgments}

We acknowledge the 300 women and children who allow us to record their pain and recovery and who take emotional risks each time we meet. As one woman said, "I want to talk but it hurts to remember." We thank each woman who chose to remember and dedicate the findings of this research to her courage and determination.

\section{Funding}

The Houston Endowment in Houston, TX funded the research of this report.

\section{References}

1. Garcia-Moreno C, Jansen HA, Ellsberg M, Heise L, Watts CH (2006) Prevalence of intimate partner violence: findings from the WHO multicountry study on women's health and domestic violence. Lancet 368: $1260-1269$.

2. Papademetriou DG (2005) The Global Struggle with Illegal Migration: No end in sight.

3. United Nations Department of Economic and Social Affairs (UN DESA), Trends in International Migrant Stock: The 2008 Revision.

4. Capps R, Bachmeier JD, Fix M, Van Hook J (2013) A demographic, socioeconomic, and health coverage profile of unauthorized immigrants in the United States. Migration Policy Institute.
5. International Organization for Migration (2006) Female migrants: Bridging the Gaps throughout the life cycle. Selected Papers of the UNFPA-IOM Expert Group Meeting, New York.

6. Decker, MR, Raj, A, Silverman, JG (2007) Sexual violence against adolescent girls: Influences of Immigration and acculturation. Violence Against Women 13: 498-513.

7. International Organization for Migration (2009) Working to prevent and address violence against women migrant workers.

8. Bustamante AV, Fang H, Garza J, Carter-Pokras O, Wallace SP et al. (2010) Variations in Healthcare Access and Utilization Among Mexican Immigrants: The role of documentation status. J Immigr Minor Health 14: 146-155.

9. Raj A, Silverman J (2002) Violence against Immigrant Women: The roles of culture, context, and legal immigration status on intimate partner violence. Violence Against Women 8: 367-389.

10. United Nations Secretary-General. (2006) Ending violence against women: From Words to Action - Study of the Secretary-General.

11. U.S. Citizenship and Immigration Services (2008) Fact Sheet USCIS issues guidance for approved violence against women act (VAWA) self petitioners.

12. U.S. Citizenship and Immigration Services (2013) Battered spouse, children \& parents.

13. U.S. Citizenship and Immigration Services (2011) Victims of criminal Activity: U nonimmigrant status.

14. Ingram M., McClelland DJ, Martin J, Caballero MF, Mayorga MT, Gillespie K (2010) Experiences of Immigrant Women Who Self-Petition Under the Violence Against Women Act. Violence Against Women 16: 858-880.

15. Moynihan B, Gaboury MT, Onken KJ (2008) Undocumented and unprotected immigrant women and children in harm's way. J Forensic Nurs 4: 123-129.

16. McFarlane J, Nava A, Gilroy H, Paulson R, Maddoux J (2012) Testing two global models to prevent violence against women and children: Methods and baseline data analysis of a seven-year prospective study. Issues Ment Health Nurs 33: 871-881.

17. Derogatis LR, Lazarus L (2001) Brief symptom inventory-18.Administration, Scoring and procedures manual.

18. Breslau N, Peterson EL, Kessler RC, Schultz LR (1999) Short screening scale for DSM-IV posttraumatic stress disorder. Am J Psychiatry 156: 908-911.

19. Marshall L (1992) Development of the Severity of Violence Against Women Scales. Journal of Family Violence 7: 103-121.

20. Campbell JC (1986) Nursing assessment of risk of homicide for battered women. ANS Adv Nurs Sci 8: 36-51.

21. Schwarzer R, Jerusalem M (1995) Generalized self-efficacy scale. Measures in health psychology: A user's portfolio.

22. Koci A (2004) Marginality, abuse and adverse health outcomes in women. Doctoral Dissertation, Emory University.

23. Norbeck JS, Lindsey AM, Carrieri VL (1981) The development of an instrument to measure social support. Nurs Res 30: 264-269.

24. Norbeck JS, Lindsey AM, Carrieri VL (1983) Further development of the Norbeck social support questionnaire: Normative data and validity testing. Nurs Res 32: 4-9.

25. Marín G, Sabogal F, VanOss Marín B, Otero-Sabogal F, Pérez-Stable EJ (1987) Development of a short acculturation scale for Hispanics. Hispanic Journal of Behavioral Sciences 9: 183-205.

26. Nava A, McFarlane J, Gilroy H, Maddoux J (2013) Acculturation and Associated Effects on Abused Immigrant Women's Safety and Mental Functioning: Results of Entry Data for a 7-Year Prospective Study. J Immigr Minority Health.

27. Harris A, Eichlin L, McArthur K, Nava A, McFarlane J (2010) Parent teacher organizations as partner to reduce obesity and prevent diabetes in a Hispanic community. Texas Public Health Journal 62: 38-40. 
Citation: $\quad$ Nava A, McFarlane J, Maddoux J, Montalvo-Liendo N, Gilroy H, et al. (2014) Characteristics of Immigrant Abused Women Who Apply for Legal Status. Arts Social Sci J S: S1-001. doi:10.4172/2151-6200.S1-001

28. Ryan DA, Benson CA, Dooley BA (2008) Psychological distress and the asylum process: A longitudinal study of forced migrants in Ireland. J Nerv Ment Dis 196: 37-45. 